\title{
Care dialogues: shifting family engagement from risk to rights in the USA
}

Tonya D. Bibbs* ${ }^{*}$

*Correspondence:

TBibbs@erikson.edu Erikson Institute, $451 \mathrm{~N}$ LaSalle Dr, Chicago, IL 60654, USA

\begin{abstract}
Though family engagement has become a priority in early childhood education and care, there are problems in our understanding of the phenomenon. First, there is uncertainty about the target of outcomes - namely, should it be children or families? Second, the early childhood field lacks ethical guidance to address the complexity of this relationship. Finally, the field has not articulated the political potential of family engagement. This paper responds to the problem by developing "care dialogues" as a framework for ethical engagement. There are two dimensions. The ethical dimension builds upon dialogue's potential for change, and the importance of recognizing particular relationships. The political dimension defines rights as the ability to act within those relationships. As a framework, care dialogues attend to the respective needs, rights, and beliefs of particular early childhood institutions and families while connecting to larger political concerns. The paper uses focus group data to build an illustrative case study demonstrating care dialogues' potential to inform early childhood practice under non-ideal circumstances. This methodological choice is critical to allaying concerns about care as a utopian approach. Using the parameters of care dialogues, the case study addresses three themes - getting personal, agency and care, and narrative as advocacy. The case study concludes that: care dialogues facilitate intimate relations essential to family engagement; the concept of inappropriately adaptive preferences addresses the agency problem; and the political impact of care dialogues extend beyond the immediate exchange between families and institutions. The implications of care dialogues to policy are discussed.
\end{abstract}

Keywords: Family engagement, Dialogue, Early childhood education and care, Rights

\section{Background}

Family engagement has become a significant priority in early childhood education and care. Empirical work has shown a broad range of positive outcomes, including higher student performance, fewer behavioral problems, and an improved attitude toward school (Hampden-Thompson and Galindo 2017; Christenson and Reschly 2010). This exclusive concern with child outcomes focuses family engagement on the role of families in meeting school-defined goals and neglects the participation of families in developing normative aims for their children's education and care. I refer to both education and care for two reasons. First, I maintain the necessity of the role of caring acts within education as more technological approaches are prioritized. Here, I am in agreement with scholars such as Dahlberg, Moss, Pence and Noddings (Moss et al. 2007; Dahlberg

(C) The Author(s) 2018. This article is distributed under the terms of the Creative Commons Attribution 4.0 International License (http://creativecommons.org/licenses/by/4.0/), which permits unrestricted use, distribution, and reproduction in any medium, provided you give appropriate credit to the original author(s) and the source, provide a link to the Creative Commons license, and indicate if changes were made. 
and Moss 2005; Noddings 2015) Second, I want to include early providers who, though they may view their primary goal as providing care, are also affording young children the developmental foundation for learning-e.g., family child care (Bromer 2001).

In her essay "Freedom for Literacy and Literacy for Freedom: the African-American Philosophy of Education" (Perry 2003) early education scholar Theresa Perry argues that linking black children's achievement to discrete academic outcomes dismisses a critical sustaining factor. Namely, it ignores a critical historic truth that even without the rewards systems of employment, admittance into institutions of higher education, or full citizenship, education has been linked to black people's identity as free people. She demonstrates how this philosophy has been instantiated in oral and written narratives, and played a discursive role in the formation of black children's identity as learners and intellectual beings. Within this logic, achievement cannot be confined to improved scores. Rather, it would need to reflect outcomes related to positive ethnic identity and community uplift.

In the book Con Respeto (Valdés 2017), educational researcher Guadalupe Valdès produces an ethnographic portrait of ten Mexican immigrant families with young children (5- tp 6-year-olds). The families in the study were located in a southwestern city bordering Texas and Mexico. Three of the families had one newly immigrated parent, while the remaining seven had two. Valdès uses a combination of participant observation and interviews to investigate parents' emic child-rearing views. She found that found that, contrary to institutional beliefs, the families did have an interest in education. However, it was not central to their ideas of a successfully raised child. Instead, they were concerned with their child's physical well-being, ability to make a living, and capacity to express culturally appropriate norms of respect. Their goals were not connected to the function of mass schooling in an industrialized society. In fact, given the limited access to education in the rural regions of Mexico from which they migrated, none of them knew anyone who had "made it" as a result of education. Successfully raised children were those who were able to achieve relatively modest goals such as having basic necessities, being hard working, avoiding premarital pregnancy, and maintaining intergenerational ties.

The first example constitutes families whose achievement goals could be considered broader than simple student outcomes, while the second locates success outside of school. In both cases, notions of achievement and success are incongruent with those driving current school achievement efforts. Family engagement practices and policies ought to provide a bridge that enables institutions and families to address these normative differences.

In Democratic Education (1999), political theorist Gutmann, argues that democratic education is politicized when authority over education policy is shared by citizens, families, and schools. Rather than rely on either expert knowledge to prescribe policy aims or the moral beliefs of families, she develops a democratic theory that relies on public debate to deliberate educational policy. This theory assumes that there will be moral disagreement between parties and acknowledges that the process of deliberation is not likely to resolve them. However, she asserts: 
We can publicly debate educational problems in a way much more likely to increase our understanding of education and each other than if we were to leave the management of schools to...enlightened experts" (Gutmann, 1999. p. 11).

Within this democratic process, the families described by Theresa Perry and Guadalupe Valdès along with education and care institutions and invested citizens would have opportunities to publicly air disagreements. Each would bring and maintain their moral commitment-unless they are otherwise convinced-but the guiding virtue is maintaining the political ideal of democratic deliberation.

Legal scholar Eichner (2010) argues that families are a central political institution whose capacities should be supported by the state. This support is predicated on the assumption that families have legitimate dependence needs and an ethic of care obligates that state to be responsive. She asserts that even when policy does not have families in mind, it affects families' functioning. Disjunctive policies assume that the state will take responsibility for families when families have failed. Child welfare policies that remove children from homes subsequent to abuse exemplify this category. Conjunctive policies assume that families and the state share responsibility for optimizing the capacity of families to care for their dependency needs. Providing universal home visiting to new mothers serves as an example here. She argues that an ethics of care demands conjunctive policies that acknowledge both the universality of family dependency needs and the role of the state in developing societal institutions that scaffold their ability to care for dependents. Therefore, the state would develop schools so that they optimize the capacity of families to engage in their educational goals.

Gutmann calls for a deliberative process that establishes families as a critical political actor in establishing democratic education policy. Eichner makes a broader claim regarding the responsibility of the state to a political family with expected dependency needs. In both cases, families have a right to act as collaborators in their children's education from a particular cultural perspective. These political ideals place political authority between stakeholders and have the potential for politicizing the context of early education and care. As I will discuss in my review of extant family engagement literature, though early childhood expresses a moral concern for family's involvement, it does not situate this activity as part of a larger political project. As Gutmann and Eichner suggest, this omission both falls short of the aims of democratic education and ignores the responsibility of the state to families as political actors. Care dialogues provides a means to address these concerns in early childhood education and care.

This paper argues that articulating an ethical-political commitment to reciprocal participation between families and institutions responds to a significant gap in the family engagement literature. Such a commitment would force us to ask who are the recipients of family engagement outcomes and whose interest do they serve? This paper will argue that not only should both home and education and care institutions design norms and receive positive outcomes, but that without this collaboration family engagement will not transform the political context of early education and care.

The current context often regards early childhood and its institutions as sites of technical achievement, as opposed to spaces for ethical and political 
activity (Dahlberg and Moss 2005). Influenced by Dahlberg and Moss, I define technical achievement as the tendency to view families as a means to predetermined child outcomes. We hear this view, for example, in the common refrain that "families undo the gains children make in school". The goal then becomes reforming families so that they no longer pose a risk to children's educational achievements. Reduced to a risk factor to be addressed, it becomes difficult for families to engage in their children's education and care as full rights-bearing agents.

This paper innovates and proposes "care dialogues" as an ethical and political guide for this social arrangement. As a guiding logic, care dialogues offer a place for both families and institutions to set the aims for education and care while attending to larger political processes. A care dialogue is the dynamic interplay between home and education and caregiving institution with the goal of developing social arrangements that meet shared aims and foster the fulfillment of rights. To develop the dimensions, I first articulate the often implicit ethical-political dimensions of family roles in three disparate formulations of family engagement in extant research: instrumental, cultural continuity/discontinuity, and collective. Though my chief concern is with early education and care, I include literature from primary schools. Early education and care programs are increasingly located in K-8 public schools. Primary grade teachers are often placed in early childhood classrooms without training particular to this age. Therefore, their views are relevant to this current discussion. Second, I present the conceptual parameters of care dialogues, highlighted by a case example. In closing, I discuss the implications of care dialogues to practice and policy.

\section{Instrumental engagement}

Instrumental approaches focus on reforming families to align their practices with those of the school to improve test scores or universalize emotional regulation practices. In this regard, families are treated as a means to an end. While families certainly make an important contribution to children's outcomes, I take aim at education and care organization's dismissal of family priorities and social position.

Educational researcher Christianakis' (2011) qualitative study investigated teachers' constructions of family engagement. She conducted 3, 1-h interviews, with 15 teachers, working in an under-resourced urban Northern California racially diverse (primarily African-American, Latino and Southeast Asian) elementary school. The teachers' racial background was representative of the student population. She found that teachers viewed themselves as supervisors of parents and viewed parents as "helpers" within the school and home to accomplish their teaching work and meet state standards. The "help labor" that parents performed within the school included running a classroom center, helping children with special needs, and performing administrative tasks. At home, help labor was characterized by a parent "practicing, reinforcing and supporting school learning at home" (p. 168). Because they were under a great deal of pressure to meet state standards, the teachers emphasized math and literacy activities. These data suggest that teachers' instrumental constructions of families are not simple reflections of an individual teacher's internal representation or set of beliefs. They are more complex and influenced by the availability of material resources and the expectations of the policy 
environment. As a result, we may find more under-resourced settings adopting instrumental views of families.

\section{Cultural continuity and discontinuity}

Early education and care has a long tradition of viewing poor and racially marginalized families as having little regard for or interest in the flourishing and well-being of their children (Lewis 1966; Payne 2005). Policy makers and practitioners point to families' lower participation rates, problematic child-rearing values, and maladaptive practices as evidence of their impoverished culture. As a result, they apply global norms of education and care across disparate groups. Those who do not meet these norms are seen as deficient.

In response to this historical trend, contemporary scholars and practitioners proposed a counter narrative asserting that families' home cultures have value that enriches children's formal education and care experiences (González et al. 2006). This literature assumes that culture influences global conceptions of education and care and investigates how differences between school and families affect engagement.

Halgunseth's (2009) model of family engagement proposes an ecological model specific to early childhood. In this model, both the school and home contribute "resources" to positive child and family outcomes. The resources include volunteering, reinforcing learning at home, and serving as a board member. Programs are responsible for initiating "two-way" communication, visiting family homes, and sharing decision making. The outline of the model creates the opportunity for mutuality and power sharing within family engagement. It can be enhanced by specifying the nature of the exchanges it specifies. For example, how do home visits contribute to equitable relations and how are power differential addressed when making decisions?

Scribner et al. (1999) investigation highlights how ethical frameworks might lead to different educational approaches. They conducted a qualitative study in high performing, predominately Hispanic, K-12 schools. They found that teachers tended to define family engagement as activities that supported academic achievement, while parents viewed involvement as supporting the total well-being of children. Reese et al. (1995) achieved similar findings in their longitudinal study of Mexican and Latin American immigrant families. Their participants believed that "the most important preparation for their child's education was to give the child a strong moral foundation" (in Okagaki and Bingham 2010, p. 82). In addition to these differences, the literature has identified disparate literacy development models. Weigel et al. (2006) found differences in models across socioeconomic groups. Lower-income families were more likely to emphasize direct instruction and basic literacy, while middle-income families promoted reading a book, and activities embedded in play and everyday activities. This literature suggests that families have both divergent means to achieving goals and ideal ends of a "successful" child. Furthermore, when the cultural differences between education and care institutions and families are hierarchically ranked, families are marginalized from their child's school and care experience.

Mapp and Hong's (2010) literature is instructive here. The authors suggest that when schools talk about "hard-to-reach" families, they are referring to poor, less formally educated, ethnic minority, dual-language, and immigrant families. Based on their findings, 
Mapp and Hong assert that for many of these families child-serving institutions are "hard to reach". They back this claim with three themes from empirical studies. Institutions are hard to reach when: their core beliefs are incompatible with families; when institutions are too focused on head counts and the dissemination of information; and when they use narrow definitions of family engagement. Instead they suggest inclusive processes grounded in building trust between schools and families.

A study by Ramirez (2008) illustrates institutions seen as hard to reach. She interviewed Latin American immigrant mothers $(n=29)$ and fathers $(n=14)$ of elementary school children. Parents reported that teachers and school officials avoided communicating with them due to language differences. They also believed that teachers had lower expectations of their children. Some parents indicated they were afraid if they voiced concerns the school might retaliate against their children or they might face deportation. In other words, their actions were influenced by an assessment of the potential risk of engaging in their child's education. As demonstrated in the current literature, the construct of culture plays opposing roles, depicting families as impoverished, as a valuable source for nurturing care and education in formal settings, and as a means of placing certain families out of institutional reach.

\section{Collective engagement}

The collective approach to early education and care assumes that families have shared interests beyond their individual needs. Early education and care institutions view them as collaborators and seek their full participation. An intervention designed by social work researcher Alameda-Lawson (2014) highlights the role of the social worker in facilitating democratic practices within a school environment. The study was conducted within a school attended by low-income African-American children. Alameda-Lawson et al. developed a model of "collective parent engagement". Rather than focusing on the individual change of parents, collective parent engagement views parents as a group that can improve academic outcomes by transforming urban schools and neighborhoods. The program had three phases: (1) Social workers worked with individual families to develop their initial confidence about being engaged in a project in the school and community. Parents then collaborated with social workers to identify the needs and challenges that threatened the well-being of their children, themselves and their community. (2) Parents identified community resources for addressing concerns and recruited additional parents from their personal networks. (3) Parents implemented programs that addressed their priority issues and the social workers' participation lessened.

Ultimately, parents designed a variety of programs reflecting the needs and challenges identified in the planning process. Programs included: (1) a home visitation and outreach program designed to engage socially isolated and excluded families in school and community events; (2) a school-based referral and information center for families in need of formal social and health services; (3) a classroom intervention team for students experiencing behavioral challenges; and (4) a student-to-student mentoring program to foster leadership development among students. In addition to this program development, project evaluators found that parent empowerment was positively and significantly related to improvement in academic achievement. 
The collective view of families brings us closer to what I have in mind with care dialogues. It both recognizes how a family's social position and group membership might affect its interaction with an early education and care institution and it seeks to expand families' agentic opportunities. From this empirical point I begin my theoretical elaboration of care dialogues.

\section{Care dialogues defined}

A family engagement care dialogue is the dynamic interplay between home and a caregiving institution with the goal of developing social arrangements that meet shared aims and foster the fulfillment of rights. They include important care ethic themes, emphasizing responsive relationships, attention to context, the integration of ethics with politics, and the affirmation of emotions based in an ethical stance (Engster and Hamington 2015). Following Bakhtin, they also assume that dialogue has the capacity for interpersonal and political transformation (Bakhtin 2010). Dialogue serves as a vehicle for linking everyday events to the broader social concerns of marginalized families, and education and care institutions. They can occur at the interpersonal level of everyday interaction, as part framing texts for relational policy, and at the macro level of shifting ideology. In so doing, care dialogues recognize and build upon the political nature of quotidian experience. I will elaborate below on how everyday dialogue supports the fulfillment of rights. The care dialogue approach shifts family engagement from the binary of either being focused on the agenda of caregiving institutions or family needs to creating a space for mutual constitution. Care dialogues focus our attention simultaneously on a description of the current situation and the possibility of equitable social arrangements that could appear between families and caregivers within institutions as they participate in dialogue. Care dialogues have two dimensions: ethical and political. The ethical dimension refers to the role of dialogue in creating a space for mutual understanding, collaboration and productive conflict. The political dimension refers to the linkages between an individual dialogical encounter and the multiple macro dialogues it embodies and generates. Herein a macro dialogue is formed at the broader ideological level of developmental influence and includes racism, gender discrimination and class marginalization.

\section{Ethical dimension}

The ethical dimension draws upon Mikhail Bakhtin's (2010) theory of dialogical imagination wherein dialogue serves as a driving force for change. Philosopher of education Olga Kovbasyuk (2011) describes his contribution as follows:

"According to...Bakhtin, dialogue entails such quality relationships between interlocutors as mutuality, responsibility, engagement and acceptance. The existential interpretation of dialogue holds that it is only in true dialogic relationships that an individual is able to unfold and experience self... as personality. Personality is different from individuality. While individuality can be described by a unique combination of individual characteristics and attributes, personality is defined by the human capacity to become the subject of one's life - the one who is able to take full responsibility for one's own actions in life" (Kovbasyuk 2011). 
Therefore, everyday dialogue creates an agentic force wherein participants enact both shared and divergent desires, while conveying culturally important ideas and negotiating meaning. Within a care dialogue, these ideas might include participants' mental models of success, toilet training beliefs, discipline practices, scripts for a well-educated child, and presuppositions about the respective roles of parents and teachers. Care dialogues also serve as a site for contesting such ideas.

Care dialogue's ethical commitments are further influenced by early childhood scholars Dahlberg and Moss (2005) whose framework challenges universal ethical approaches. These rely on an autonomous human being making ethical decisions outside of the experience of everyday life. Therein, the context of the ethical act is subjugated to principles that are assumed to apply to all persons. Instead, Dahlberg and Moss promote a person who is actively engaged in particular relationships. The specific contextual conditions of that relationship, along with universal principles influence the ethical assessment. Rather than assume that families need to be told what is right or wrong regarding their child's educational flourishing; they are entrusted with the ability to arrive at ethical decisions with minimal moral proscriptions from educational authorities.

\section{Political dimension}

The political dimension focuses attention on a relational concept of rights. It prioritizes the relationship between public and private affairs as well as interpersonal relationships as the milieu in which we exercise rights. I propose that when care dialogues bring family matters into the public sphere of early childhood programs and policies; both families and formal caregivers have the opportunity to make changes necessary to increasing their capacity to act on behalf of children.

Political scientist Joan Tronto points to a problem with current approaches to rights.

"Being a moral person is thus, almost by definition, linked to the ability and the authority to exercise rights and fulfill obligations" (Tronto in Dahlberg and Moss 2005, p. 67).

How does this view of rights apply to family engagement? First, it assumes that individuals have equal access to action. In other words, families that want to engage in their children's education and care have access to the means of engagement. Second it does not express moral regard to those who, for whatever reason, have not met an established threshold of moral conduct. If these families do not have moral worth, then what kind of regard can they expect from education and care institutions? Finally, it assumes that there ought to be a distributive agent who assesses families' acts and assigns them to a moral category. In other words, families that do not engage with education and care institutions appropriately lose their moral worth and families without moral worth are not deemed worthy of engagement as full agents. They are risks to be managed and reformed.

Political theorist Iris Marion Young's (2002) conceptualization of rights, which I incorporate into care dialogues, provides a counter arrangement. She asks:

"What does distributing a right mean? One may talk about having a right to a distributive share of material things, resources, or income. But in such cases it is the good that is distributed, not the right... Rights are not fruitfully conceived as pos- 
sessions. Rights are relationships, not things; they are institutionally defined rules specifying what people can do in relation to one another. Rights refer to doing more than having, to social relationships that enable or constrain action" (Young 2002, p. 25, emphasis in original).

Here, the realization of rights occurs as an aspect of an ethical interaction. As political theorist Virginia Held states in her political framework of care ethics, rights presume a background of social connectedness (Held 2006). Thus ethics and rights are co-constitutive. Within a care ethics framework, family engagement practices and policies would seek to maximize the agency of families and nurture collaborations between home culture and early education and care settings. Importantly, care ethics also acknowledges that there are moral issues arising between unequal, involuntary, and dependent relations. Within early education and care, these inequities exist due to power granted to professional caregivers by virtue of their institutional affiliation. Structural inequalities such as race, gender, immigration status, and ability also circumscribe relationships. Care dialogues cannot ameliorate institutional or structural oppression. However, as a local politics, they can create a space for integrating these concerns into the official work of early education and care, thereby fostering the emancipatory potential of both institutions and formal caregivers and families.

\section{The context of marginalization}

As Bakhtin reminds us, an utterance within a given dialogue is always referencing other dialogues. He named this phenomenon multivocality. With regard to engagement with socially and economically marginalized families, I am concerned with the ways in which education and care institutions understand the embeddedness of families within oppressive dialogues that construct marginalization. Grasping such a perspective would require that institutions have some preunderstanding of social positioning and its effect on child development, family life, and academic achievement. While the degree to which these multiple dialogues intersect with a given care dialogue will vary, awareness of these background conditions is critical to understanding a family's complete experience. Likewise, the constructive use of care dialogues increases when families understand the multiple organizational and political pulls early education and care programs experience. Care dialogues are at once intersubjective-occurring between an institution and a particular family-and multivocal, interacting within a web of broader discourses.

\section{Illustrative case study}

To demonstrate how care dialogues might contribute to a shift in social arrangements, I present below narratives extracted from focus groups with Head Start parents and Head Start directors. Although outlining the history of family engagement within Head Start is beyond the scope of this paper, it is important to note that since the program's inception in 1965 there has been considerable disagreement on how to interpret the role of families and communities in positive child outcomes. While some policy makers and program directors have viewed families instrumentally as helpers in need of reform, others have advocated for a collectivist model of family engagement (Zigler and Styfco 2004). As such, participants in Head Start focus groups were speaking within a history that embodies this tension. The Head Start director and parent focus group 
participants were speaking within a history that embodies this tension and reflects their current interpretation of family engagement. Overall, ten focus groups throughout Illinois were conducted over a period of 4 months. A total of 69 individuals participated: 42 early education and care staff and 27 parents or caregivers. The goal of the focus groups was to interview families and directors, who had attained gold standard family engagement practices according to Illinois' early childhood quality rating system. Program staff were asked to discuss best practices for family and community engagement and supports needed in these areas. Parents were encouraged to discuss what makes a program exceptional with respect to family and community engagement. Each group's attendance ranged from 5 to 14 participants (Bromer and Weaver 2014). For the purpose of illustrating care dialogues, I draw from two of these Head Start focus group transcripts. The parent focus group had 11 mothers. Two of them were African-American and the remaining participants were white. The program staff had ten directors-two males and eight females. Two of the participants were African-American and the others were white.

My intent is to show the promotion of care dialogues as well as factors constraining them. In so doing I aim to ground the theoretical horizon of care dialogues in the nonideal circumstances of early education and care practice. This illustration counters any utopian charge regarding care dialogues as unrealistic and unattainable. The case study organizes focus group discussion into three themes-getting personal, coercing care, and narrative as advocacy-and analyzes the contribution of each to care dialogues.

\section{Getting personal}

Focus group participants highlighted both the development of their initial working relationship and the transformation that occurred. Their comments suggest that intimacy and appropriate other regarding behavior establish the motivation for action. The intimacy they describe develops from an often reluctant beginning, as illustrated by an exchange that preceded Linda's significant family engagement shift:

To get personal, when I was pregnant with my first son I was couch to couch. I was comfortable on the couch watching TV all day, didn't want to do nothing. I didn't know what to do, I didn't have a place to go and then I heard about Head Start - well, Early Head Start, so I got involved and it wasn't just about the child and then that's where I saw that there was a difference between the regular public school program and you know Head Start. Because they helped me, you know they took me under their wing and they're like okay, well, let's go, you know look at Section 8 (rental assistance to low-income families), let's go do this, let's go do that. You know along with helping my child.

Here, Linda describes the process of becoming intimate under conditions of economic and social isolation. She is living on friends' couches, and withdrawn into watching television all day. Her report that it "wasn't just about the child" suggests the significance of their interest extending beyond the instrumental goal of seeing her as means to the child to seeing her as a person.

Linda continues by describing her growing capacity to participate in her children's education experience: 
And now with my child in the public school system I'm needing my ADHD (attention deficit hyper-active disorder) one, we didn't put him on an IEP (individualized education plan) because he didn't need it. You know but now he's needing a 504 (federally mandated supports for students with disabilities) enacted. And because of the processes that they've helped me go through you know I'm able to now turn around and say I know what I'm doing for my child. I know how to handle a 504 meeting. And I go in there with confidence like I said, now I'm the parent ambassador and I sit on the board and this something that seven years ago, if you knew me this wasn't me. I came out of my comfort.

The other regarding behavior in the initial dialogue invites Linda to act and eventually to emerge as an advocate for her child. Therefore, the ethical dimension enables the transformation of the political. Her use of the word "comfort" is interesting here. She describes leaving comfort, which she previously depicted as being sedentary and not wanting anything, for a place of confidence and assertion. As she moves from one space to another, the care dialogue promotes the cultivation of desire, a longing for something more. So, together with intimacy, desire contributes to the development of rights fulfillment.

Providers also discussed the ways in which they developed intimacy or a deeper understanding of families. Below Walter reflects on their process of assessment.

I think we go above and beyond more than the norm because there's never usually, very rarely a kind of a standard situation there's so many variations and differences, challenges that our families face, but I think the exceptions are really not so much about breaking the rules as they are around flexibility. I think sometimes we always end up looking at these situations and saying what do we know about the family? What do we know about the situation?

Walter's focus on understanding the individual circumstances of each family is consistent with an ethical principle of encountering the uniqueness of persons and a political priority of establishing rights within a relationship. His distinction between breaking and being flexible around the rules raises a critical issue. Care dialogues occur within a policy milieu that can constrain or enable their development. However, they are also acts that have the potential to influence policy. Put differently, they contribute to Held's agenda of developing care politics that prioritize particularity. This approach stands in contrast to the increased standardization of relationships found in early childhood policies.

The relational good of intimacy is not only experienced by families. As Held reminds us, the interests of those who care are intertwined with the particular others for whom they care. Below, director Glenda expresses the effect regarding fathers has had on their center:

I think that overcoming the staff bias is a huge part of it and then when you do have those dads that call in and say I understand that my child goes to your center, we won't deny him information unless there's some court orders that says he can't be involved. 
The presence of fathers within the care dialogue introduced a challenge. How would the center recognize fathers? Their decision to look inward at their anti-father biases they carry is a move toward democratizing the intersubjective space, and minimizing the impact of early childhood's marginalization of fathers. Though Glenda does not tell us what motivates the fathers to approach the center, it may represent an assertion of their right to care for their child, a right that is achieved within the care dialogue. Thus, the center's ability to collaborate with fathers expands and brings the center closer to its mission. The biases to which Glenda refers are not born in a given care dialogue. Rather, they connect to ongoing dialogues in the early education and care field, as well as society in general, about racially and economically marginalized fathers. Their reflection on their biases and subsequent change can be read as a form of resisting these dialogues. As discussed, resistance provides the opportunity for the mutual rights fulfillment of those who care and those for whom they provide care.

\section{Agency and care}

Both directors and parents address a potential threat to mutuality within care dialogues that bears consideration, as illustrated by Dorothy's characterization of her initial encounter with her center.

So, I got four boys, all four of them have been in and through Head Start besides my baby, he's still there and they were able you know to bring me out of my shell, like I'd never be here. And I'm like no, I'm not going to groups, I don't know those people you know I'm not going you know and she kept at it you know, she was persistent. And she kept at it and she kept at it, finally I went to group and then I was like I don't know about this you know, uh-uh, no, you're pushing me too far now. And you know then they got me in it you know, sure - slowly but surely.

As Dorothy maps the developing intimacy between her and the Head Start program she uses the words "persistent" and "pushing". She positions herself as initially reluctant and eventually influenced by the forceful action of the center. Another mother, Jolene, explains the value of her provider's approach.

"I was going to say that, with a lot of us it's their level of care... How many people have been working at their job and still have that love and care and energy? And because they have that, they're persistent with us who don't want to do anything.

Much like Dorothy, Jolene associates persistence with acts of caring. They suggest that providers are justified in "pushing" participants into doing things that are outside of their comfort zone or preferences because they want what's best for them.

In his description of working with hard-to-reach families Joshua states the following:

...so, then when I think about reaching the hardest to reach, that's what I think about is those situations where oftentimes, I don't think that we're not touching these families in many cases, we're not reaching them in the sense of making a connection with the benefit of services. And so, this to me is a bigger challenge than just offering access. And oftentimes then our only response and our only option becomes authoritative intervention because that is oftentimes what we're left with... 
In a subsequent passage, Joshua goes on to describe another family that they "incentivized to make better choices". He reports that they withheld benefits until the family committed to the consistent housing the city offered them. He feels the incentivizing is warranted due to the positive family outcomes-namely improved stability.

The use of pushing, authoritative intervention and incentivizing raise the issue of agency within a care dialogue. To address this agency concern, I incorporate philosopher Serene Khader's concept of "inappropriately adaptive preferences" into care dialogues. The underlying assumption of IAPs is that "bad social conditions influence people to form preferences that are bad for them" (Khader 2011, p. 20) and counter to the goals of basic flourishing. For example, in the context of family engagement we could consider universal parenting goals (Levine 1988) as conditions that are foundational to flourishing as a child's caregiver. Khader and other feminist philosophers caution against crafting policies based upon IAPs as they likely do not represent the preferences one would make under less marginalized conditions (Cudd 2006). Khader argues that we should focus on the dual goals of prioritizing basic flourishing and respecting people's right "to lead the type of lives they want to lead" (Khader 2011, p. 6).

Khader's ethical framing of IAPs resonate with the goals of care dialogues in that they are primarily concerned with responsive action toward the other, and consider the particular contextual conditions that inhibit or promote basic flourishing (Engster and Hamington 2015). Within a care dialogue, education institutions have a responsibility to improve the conditions of basic flourishing in which families develop their preferences. Because families have claims on educational institutions as political actors, they both contribute to the conceptualization of basic flourishing, and maintain their right to pursue their respective educational aims.

Dorothy's retrospective account suggests that her choice to be in "her shell" was desirable-if not counterproductive to her basic flourishing. She indicates that her relationship with the Head Start transformed the conditions of her choice, at which point her desire to engage in her child's education shifted. However, the positive outcome she depicts does not provide an ethical justification for the Head Start's conduct. The primary ethical question is "did the Head Start improve the conditions of basic flourishing". This framing emphasizes the institution's duty while maintaining Dorothy's capacity to act within the relationship.

Joshua's use of the phrase "authoritative intervention" places an emphasis on the relative status positions of the institution and the family. He notes that they withheld benefits until the family made decisions that were better for them, which the family eventually did. Again, the fact that the family eventually made a choice that "seemed" in their best interest is not the pivotal issue. Rather, the focus is on the duty of the Head Start to improve the basic flourishing conditions of the family's preference formation. Joshua's account suggests an "ends justifies the means" rationale providing no evidence of improving the conditions of preference formation. His approach to IAPs does not meet the relational standards for a care dialogue as it does not respect the family's choice to lead the type of lives they want to live. Instead, it presents a contractual relationship whose logic asserts "if you want $a$, you must choose $b$ ". 
It is likely that marginalized families will come to the family engagement table with more IAPs than others. Khader's approach provides a framework to address them within the goals of a care dialogue.

\section{Narrative as advocacy}

Care dialogues are active at an additional level of performance as they extend from the interpersonal to the public and policy arenas. A care dialogue that takes place between providers and families can be archived in the form of a narrative and used for the purpose of advocacy. Following feminist philosopher Meyers (2009), I claim that in this narrative form care dialogues offer an opportunity for interested parties to take "a moral interest...in events" (p. 1). In the excerpts below, a provider responds to the facilitators' initial question of "what does it mean to respect parents":

I think they [parents] still do not realize that they were the final word in terms of a decision for their child. I think they felt very much like they were being directed and being told that they were going to do rather than what their options were and so that whole advocacy and you're the final person that signs the Individual Education Plan or the Individual Family Service Plan and you're the one that makes that decision.

The goal of parents' participation includes agency over the direction of their child's service and over the proceedings themselves. The extent to which a family is able to share their personal narrative increases this capacity. The narrative becomes part of the event's official record extending the care dialogue from the personal to the public. Another focus group provider participant responds to this statement by describing a time when an organization blocked a parent's participation.

In our county, we go to the health department to get TB skin tests [and] blood drawn ... for us it seems pretty simple, go get it done. But we had a parent that came to us and shared her story and someone said will you just write it down, just write down your story from the minute you walked in until the minute you left. And [the parent] gave that to our health coordinator who called the director of the health department in County " $X$ " and said can we sit down and talk. We have tried many times, through conversations, to ... make this process easier. When [the director of the health department] read that letter or summary of how [the parent's] experience went, she was in awe... Just sharing this was [the parent's] experience from when she walked in your door until she left. That parent was able to show them how their service, not only didn't help get the service to the end user, but it also kind of pushed their mission because as a health department, they want these things too, for the population they serve.

This passage bears lengthy quoting for two reasons. It depicts the shift of a care dialogue into the form of narrative advocacy. The speaker's organization had not been able to make the desired intervention. However, when the health department was confronted with the experience of the parent and they took a moral interest in their situation, they became more reflective of the moral and political practices of their organization. In this case, the care dialogue shifts the plane of action from interpersonal experience to systems change. 


\section{Discussion}

Care dialogues embody a dialogical process that simultaneously ground family engagement work in the shared and non-shared aims of families and early education and care institutions. Their ethical and political commitments ensure that all participants have the potential for emerging into a space of greater agency and relational strength. They provide an approach to family engagement that frames everyday practice. They are especially significant when families and early education and care providers are at an impasse. They provide a guide to remaining engaged in the relationship without succumbing to typical power practices that privilege the institutional status over the rights of families. Participants optimally engage in care dialogues within a supportive policy environment. Child-serving organizations need flexibility policy parameters for family engagement that will enable them to be responsive to the needs of families. Families need policies that will enable them to have real input into the formation of education and care policies.

Care dialogues enable us to recover a notion of accountability that education policy has abandoned. Contemporary uses of the concept are saturated with intentions of meeting the terms of a contract or justifying tax payer dollars. With care dialogues, we can also consider what it means for persons, institutions, and policies to take an ethical accounting for themselves as part of a network of social interaction. Below, I consider how a care dialogue frame could inform evaluations of early education care quality.

Most North American states (Mississippi being the exception) have or are in the process of developing quality rating improvement systems (QRIS) that promote systems reform and provide standards for high quality family engagement with early education and care (https://qrisnetwork.org/). In their evaluation of centers that had received the highest family engagement rating in their state, Bibbs and Bromer (2017) found that the QRIS mechanism offered little guidance regarding the relational core of family engagement. Instead, they emphasized "welcoming activities" constructed in terms of the center's needs. Conversely, throughout the center director and staff interviews, participants discussed the various dimensions of their relationships with families and communities. Not surprisingly, they described them as the crux of engagement. Therefore, the standards reflect a less relational approach to family engagement than what occurred in everyday practice. Care dialogues provide a conceptual framework to develop QRIS standards, thereby deepening the ethical and political reach of families in early childcare.

The centers' documentation of standard achievement would flow from the care dialogue frame. They would use narrative documentation to describe the development of the engagement. For example, programs could provide narratives regarding their growing responsivity to families. Centers could also provide an example of a time when a care dialogue was used for advocacy. Of course, this more substantive documentation process would require a well-resourced, high-quality review process. However, both the conceptual framing and the rigorous review process offer more promise for QRIS' stated reform goals than current policy practice. Care dialogues, therefore, could guide the daily interactions of centers with families and the priorities of state-level evaluation.

Care dialogues have the potential to address current debates and impasses in the early childhood education and care. North America is currently considering what it means to professionalize early education and care. While the intention of these efforts is to increase the societal value of this work, its advocates have met with resistance from 
those who feel marginalized by professionalization efforts-e.g., family child care providers and the families who use their services. Their agenda has also illuminated barriers in the ability of well-qualified educators of color to pursue the proposed higher education standards, thus raising concerns about a whitening workforce. (https://www.naeyc .org/our-work/initiatives/profession, 2018; Dalli and Urban 2013; Urban 2008). Education and care providers, families and policy makers all have legitimate claims to this issue. Using a care dialogue approach, would enable stakeholders to maintain a focus on the care needs of children, the role of the state in supporting families' goals and the rights of families to pursue basic flourishing. There are currently virtual and public forms hosted by the National Association for the Education of Young Children that could serve as a venue for these care dialogues.

Though the family engagement literature frequently refers to the importance of a relationship-based approach, it does not describe the ideal ethical and political parameters of the interpersonal exchange. I develop care dialogues as a framework, grounded in the non-ideal circumstances of everyday practices, and propose them for everyday use in early childhood and care settings. This manuscript constitutes an initial attempt to frame the concept and consider how they might be used. Next steps should address specific practice and policy opportunities to operationalize and integrate them. Opportunities that are less affected by political vacillations-such as QRIS standards-would be preferred over those that rely on compatible ideology of state or federal administration. One might claim that the fields' current emphasis on relational practices addresses the issues raised in this manuscript. However, referencing the image of a relationship without explicating how it is assembled socially provides insufficient practice and policy guidance. To continue aligning practice and policy with the values of so-called "relational practice", we will need to continue clarifying disparate articulations of relating.

Authors' contributions

The author read and approved the final manuscript.

Competing interests

The author declares no competing interests.

The manuscript has not been published, or submitted for publication elsewhere. This manuscript is not be submitted for a special issue.

Funding

There is no funding source to declare for this manuscript.

Publisher's Note

Springer Nature remains neutral with regard to jurisdictional claims in published maps and institutional affiliations.

Received: 14 January 2018 Accepted: 30 November 2018

Published online: 07 December 2018

\section{References}

Alameda-Lawson, T. (2014). A pilot study of collective parent engagement and children's academic achievement. Children \& Schools, 36(4), 199-209.

Bakhtin, M. M. (2010). The dialogic imagination: Four essays (Vol. 1). Austin: University of Texas Press.

Bibbs, \& Bromer, (2017). Strengthening early childhood program quality: An evaluation of Illinois' Award of Excellence in family and community engagement. Chicago: Herr Research Center for Children and Social Policy.

Bromer, J. (2001). Helpers, mothers, and preachers: the multiple roles and discourses of family child care providers in an African-American community3. Early Childhood Research Quarterly, 16(3), 313-327.

Bromer, \&Weaver, (2014). Going above and beyond. Chicago: Herr Research Center for Children and Social Policy.

Christenson, S. L., \& Reschly, A. L. (Eds.). (2010). Handbook of school-family partnerships. Abingdon: Routledge. 
Christianakis, M. (2011). Parents as" help labor": Inner-city teachers' narratives of parent involvement. Teacher Education Quarterly, 38(4), 157-178.

Cudd, A. E. (2006). Analyzing oppression. Oxford: Oxford University Press.

Dahlberg, G., \& Moss, P. (2005). Ethics and politics in early childhood education. Abingdon: Routledge.

Dalli, C., Urban, M., \& (Eds.). (2013). Professionalism in early childhood education and care: International perspectives. New York: Routledge.

Eichner, M. (2010). The supportive state: Families, government, and America's political ideals. Oxford: Oxford University Press. Engster, D., \& Hamington, M. (Eds.). (2015). Care ethics and political theory. Oxford: OUP Oxford.

González, N., Moll, L. C., \& Amanti, C. (Eds.). (2006). Funds of knowledge: Theorizing practices in households, communities, and classrooms. Abingdon: Routledge.

Gutmann, A. (1999). Democratic education. Revised edition. Princeton: Princeton University Press.

Halgunseth, L. (2009). Family engagement, diverse families, and early childhood education programs: An integrated review of the literature. YC Young Children, 64(5), 56

Hampden-Thompson, G., \& Galindo, C. (2017). School-family relationships, school satisfaction and the academic achievement of young people. Educational Review, 69(2), 248-265.

Held, V. (2006). The ethics of care: Personal, political, and global. Oxford: Oxford University Press on Demand.

Khader, S. J. (2011). Adaptive preferences and women's empowerment. Oxford: Oxford University Press.

Kovbasyuk, O. (2011). Dialogue as a means of change. The International HETL Review. (Vol. 1, Article 2). https://www.hetl. org/opinion-articles/dialogue-as-a-means-of-change/.

LeVine, R. A. (1988). Human parental care: Universal goals, cultural strategies, individual behavior. New Directions for Child and Adolescent Development, 1988(40), 3-12.

Lewis, O. (1966). The culture of poverty. Scientific American, 215(4), 19-25.

Mapp, K. L., \& Hong, S. (2010). Debunking the myth of the hard to reach parent. Handbook of School-Family Partnerships, $10,345-361$.

Meyers, D. T. (2009). Narrative structures, narratives of abuse, and human rights. In L. Tessman (Ed.), Feminist ethics and social and political philosophy: Theorizing the non-ideal (pp. 253-269). Netherlands: Springer.

Moss, P., Dahlberg, G., \& Pence, A. (2007). Beyond quality in early childhood education and care: Languages of evaluation. Abingdon: Routledge.

Noddings, N. (2015). Care ethics and "caring" organizations. Care Ethics and Political Theory, pp. 72-83.

Okagaki, L., \& Bingham, G. E. (2010). Diversity in families. Handbook of school-family partnerships, pp. 80-100.

Payne, R. K. (2005). A framework for understanding poverty.

Perry, T. (2003). Freedom for literacy and literacy for freedom: The African-American philosophy of education. Young, gifted, and black: Promoting high achievement among African-American students, pp. 11-51.

Power to the profession. (2018). Retrieved from https://www.naeyc.org/our-work/initiatives/profession.

Quality rating information systems. (2018). Retrieved from https://qrisnetwork.org/.

Ramirez, A. Y. (2008). Immigrant families and schools: The need for a better relationship. In T. Turner-Vorbeck \& M. M. March (Eds.), Other kinds of families: Diversity in schools and culture (pp. 28-45). New York: Teachers College Press.

Reese, L., Balzano, S., Gallimore, R., \& Goldenberg, C. (1995). The concept of educación: Latino family values and American schooling. International Journal of Educational Research, 23(1), 57-81.

Scribner, J. D., Young, M. D., \& Pedroza, A. (1999). Building collaborative relationships with parents. Lessons from highperforming Hispanic schools: Creating learning communities, 36-60.

Urban, M. (2008). Dealing with uncertainty: Challenges and possibilities for the early childhood profession. European Early Childhood Education Research Journal, 16(2), 135-152.

Valdés, G. (2017). Con respeto: Bridging the distances between culturally diverse families and schools: An ethnographic portrait. New York: Teachers College Press.

Weigel, D. J., Martin, S. S., \& Bennett, K. K. (2006). Contributions of the home literacy environment to preschool-aged children's emerging literacy and language skills. Early Child Development and Care, 176(3-4), 357-378.

Young, I. M. (2002). Inclusion and democracy. Oxford: Oxford University Press on Demand.

Zigler, E., \& Styfco, S. J. (2004). The Head Start Debates. Baltimore: Brookes Publishing Company.

\section{Submit your manuscript to a SpringerOpen ${ }^{\circ}$ journal and benefit from:}

- Convenient online submission

- Rigorous peer review

- Open access: articles freely available online

- High visibility within the field

- Retaining the copyright to your article

Submit your next manuscript at $\boldsymbol{\nabla}$ springeropen.com 